\title{
PERSONALITY DIMENSIONS IN YOUNG PEOPLE WITH ANXIETY DISORDERS
}

\author{
Andromahi Naumovska ${ }^{1}$, Dimitar Bonevski ${ }^{1}$, Marija Raleva², Viktor Isjanovski ${ }^{1}$ \\ Andromahi Naumovska \\ Center for Mental Health, Psychiatric Hospital- Skopje \\ Kole Nedelkovski 52, 1000, Skopje, Macedonia \\ andromahi_n@yahoo.com \\ Dimitar Bonevski \\ Center for Mental Health, Psychiatric Hospital- Skopje \\ Kole Nedelkovski 52, 1000, Skopje, Macedonia \\ dimitarbonevski@gmail.com \\ Marija Raleva \\ Clinic of Psychiatry \\ Beogradska bb, Skopje, Macedonia \\ marijaraleva@gmail.com \\ Viktor Isjanovski \\ Center for Mental Health, Psychiatric Hospital- Skopje \\ Kole Nedelkovski 52, 1000, Skopje, Macedonia \\ viktorisjanovski@yahoo.com
}

\begin{abstract}
Introduction: The personality is a product of biological determination that is shaped under the influence of the process of socialization. Early inhibitions of certain behaviors in children are factors to later development of inhibited or timid individual. These traits continue to develop through adolescence to adulthood and increase the risk for developing anxiety disorders. Aim: This study was created to make an assessment of personality dimensions in young individuals with anxiety disorders. Material and method: For assessment of the personality dimensions the Personality Questionnaire (BTS) was administered to 40 patients with panic disorder (PD), 40 patients with social phobia (SP) and 40 patients with generalized anxiety disorder (GAD) diagnosed according ICD-10. Results: Statistically significant differences between the groups at level 0.05 were found in terms of dimension neuroticism overall and individually in relation to the traits- hostility and anxiety. From the dimension conscientiousness statistically significant differences between the groups were found for the traits- order and achievement striving $(\mathrm{p}<0.05)$. Conclusion: Young people with GAD have highest hostility and anxiety and neuroticism in general, while the one with SP have lowest. Young people with GAD and SP are most determined for order and achievement striving, while those one with PD are with less pronounced personality traits for order and achievement striving.
\end{abstract}

\section{Indexing terms/Keywords}

Panic disorder; Generalized anxiety disorder; Social phobia; Personality dimension; Young people.

\section{Academic Discipline And Sub-Disciplines}

Psychology; Medicine;

\section{SUBJECT CLASSIFICATION}

personality dimensions and traits in young people with different types of anxiety disorders

\section{TYPE (METHOD/APPROACH)}

Original research- Analytical, cross-sectional cohort study

Statistical data analyses are conducted using software SPSS 17.0.

\section{Council for Innovative Research}

Peer Review Research Publishing System

Journal: International Journal of Research in Education methodology

Vol . 6, No.3

iiremeditor@gmail.com

www.ijrem.com 


\section{INTRODUCTION}

Personality traits represent opportunities that are manifested in certain conditions and depend on the biological disposition of the person. Personality traits are stable, vary between individuals, and only apply to a certain individual. They affect individual behavior making it unique in comparison to the others (1).

According to Eysenck various personality traits are caused by the characteristics of the brain, which are influenced by genetic factors (2). He identifies the reticular formation and limbic system as a key components of the cortical reaction and then as a key components of the appropriate emotional response. Eysenck gives an explanation that extroverted have low levels of cortical arousal, while introverts have high level which leads them to look for a constant stimulation outside, in socialization. He binds psychoticism to testosterone, and to the dopamine system. Neuroticism by his opinion is still considered to be mediated by the level of excitement in the limbic system, and those with high neuroticism in small stresses exceed the level of normal activation, while those with low neuroticism under great stress does not exceed the level of normal activation (3).

Today the main factor approach for examining personality dimensions is the five factor model (five dimensionsextroversion, neuroticism, openness, agreeableness, conscientiousness), and within each dimension there are six traits included (4). The dimensions shows consistency in interviews, observations and self-describing, and are also found in various cultures at different ages (5), with no qualitative difference between normal and pathological personality except in schizophrenia or dementia states $(6,7,8,9)$.

Studies have shown that all five factors are formed and maintained both by the environment and the inheritance. So the person and its personality is a product of biological determination which is shaped under the influence of the process of socialization, as a result of the acquired attitudes, values, ideas and rules for social behavior (9). Early inhibitions of certain behavior in the children are factors for developing inhibited or timid individuals. These traits continue to develop through adolescence to adulthood and increase the risk of developing anxiety disorders. (10). Individual studies particularly emphasize the importance of the assertiveness, competitiveness and perfectionism, and the experience of negative evaluation by others as the most important psychological factors for the development of anxiety disorders (11, 12). Adolescence is a critical transition stage of development, between childhood and adulthood, in which the occurrence of anxiety disorders can still be prevented.

\section{MATHERIAL AND METHOD}

The purpose of this paper is to explore the differences in personality dimensions and traits in young people with different types of anxiety disorders (PD, GAD and SP) by conducting analytical, cross-sectional cohort study.

The sample is consisted of 120 young people (18 to 25 years; 69 female and 51 male, 40 with PD, 40 with GAD, and 40 with SP). Inclusion criteria - young people who are asking for professional help for a first time at the Center for Mental Health- "Center" at the Psychiatric Hospital "Skopje" - Skopje and Psychiatric Clinic- Skopje and are diagnosed according ICD-10 as anxiety disorders (panic disorder, social phobia and generalized anxiety disorder as the most common anxiety disorders) and who agree to participate in the study with guaranteed anonymity. All of them are high school graduates. They are selected randomly. Exclusion criteria- presence of co-morbidity with other mental disorder.

Used tool is: Five Factor Questionnaire of Personality (BTS), which contains 240 items, grouped into five main dispositions, within each of them there are 6 traits:

* Neuroticism- consisting of anxiety, hostility, depression, self-awareness, impulsivity, vulnerability

* Extroversion- consisting of warmth, gregariousness, assertiveness, activity, excitement seeking, positive emotions

* Openness- consisting of imagination, aesthetics, feelings, action, new ideas, values

* Agreeableness- trust, straightforwardness, altruism, compliance, modesty, kindness

* Conscientiousness- competence, order, dutifulness, achieving striving, self discipline, dedication

The answers are ranked on 7 degree scale (1- completely disagree, 2 mostly disagree, 3 partially disagree, 4 neither agree nor disagree, 5 partially agree, 6- mainly agree and 7 completely agree).

Internal consistency, reliability of the questionnaire, alpha coefficients are: for $\mathrm{N}$ (neuroticism) is 0.92 , for $\mathrm{E}$ (extroversion) is 0.89 , for (openness) is $0.87, A$ (agreeableness) is 0.86 and for $C$ (consciousness) is 0.90 , and the validity after 6 months period is 0.83 .

Statistical data analyses are conducted using software SPSS 17.0. For data analysis we used the following statistical methods: the distributions of continuous variables (personality dimensions and traits) are shown as- arithmetic mean and standard deviation. Differences between groups were analyzed by analysis of variance (ANOVA). All statistical tests were processed using the statistical significance of $p<0.05$ (results considered as statistically significant). 


\section{RESULTS}

The results of the analysis of the survey data by the personality dimensions in subjects with PD, GAD and SP are shown in Table 1.

Table 1. Mean and standard deviations of the personality dimensions in subjects with PD, GAD and SP

\begin{tabular}{|l|r|r|r|r|r|r|}
\hline \multirow{2}{*}{} & \multicolumn{2}{|c|}{ GAD } & \multicolumn{2}{c|}{ PD } & \multicolumn{2}{c|}{ SP } \\
\cline { 2 - 7 } & $\mathrm{M}$ & $\mathrm{SD}$ & $\mathrm{M}$ & $\mathrm{SD}$ & $\mathrm{M}$ & \multicolumn{1}{c|}{$\mathrm{SD}$} \\
\hline Agreeableness & 207.62 & 24.01 & 200.60 & 28.90 & 207.30 & 15.45 \\
\hline Extraversion & 209.90 & 28.56 & 202.38 & 35.78 & 215.32 & 22.92 \\
\hline Neuroticism & 223.85 & 22.62 & 215.10 & 29.19 & 209.88 & 21.85 \\
\hline Openness & 209.20 & 28.90 & 199.58 & 33.35 & 212.85 & 17.34 \\
\hline Consciousness & 222.18 & 32.52 & 209.15 & 38.41 & 222.58 & 22.28 \\
\hline
\end{tabular}

The results (Table 1 and Chart $1(a, b, c, d, e, f)$ ) show that the subjects with PD have lowest average score in willingness to cooperate, extroversion, openness and conscientiousness. Highest scores for extraversion and openness have subjects with SP. For agreeableness and consciousness subjects with GAD and SP have equal average scores. Lowest average scores in neuroticism have those with SP, and the highest scores in neuroticism have subjects with GAD. Neuroticism is most apparent in those with GAD, while consciousness is most apparent dimension in subjects with SP.
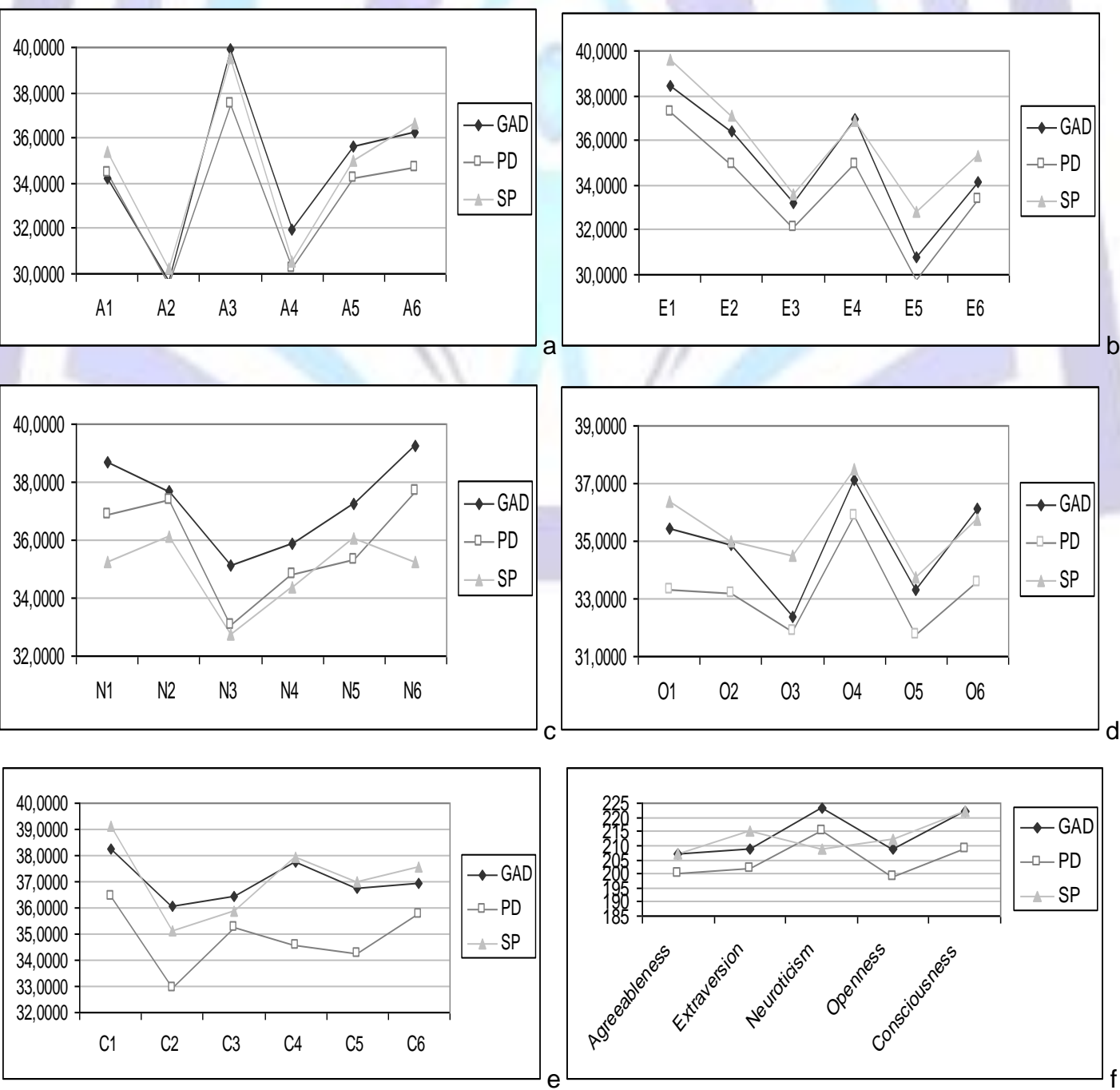
Chart 1. Personality dimensions and traits in subjects with PD, GAD and SP

Statistically significant difference $(p<0.05)$ between the groups is found only in relation to the personality dimensionneuroticism (Table 2 ). In relation to neuroticism statistically significant difference is found $(p<0.05)$ for the personality traits- severity of the anxiety (GAD- $M=38.68, P D-M=36.90, S P-M=35.28 ; F=3236)$ and vulnerability $(G A D-M=$ 39.22, PD- $M=37.68, S P-M=35.25 ; F=3$ 954) (chart. 1c).

In the dimension consciousness statistically significant differences $(p<0.05)$ is found between the groups in relation to the traits: order (GAD- $M=36.08, P D-M=32.95$, SP- $M=35.15 ; F=3308$ ) and dutifulness (GAD- $M=37.78, P D-M=$ 34.55, SP- $M=37.92 ; F=3$ 023) (chart. 1d), but not in consciousness in general. No differences were found between the groups of subjects with different anxiety disorders in openness, agreeableness and extraversion as personality dimensions and also for the traits within them (Figure 1-a, b, g, respectively).

Table 2. Test of differences between personality dimensions in respondents with PD, GAD and SP

\section{DISCUSION}

\begin{tabular}{|l|r|r|}
\hline \multirow{2}{*}{} & \multicolumn{2}{|c|}{ GAD, PD, SP } \\
\cline { 2 - 3 } & \multicolumn{1}{|c|}{$\mathrm{F}$} & \multicolumn{1}{c|}{ Sig. } \\
\hline Agreeableness & 1.143 & .322 \\
\hline Extraversion & 1.936 & .149 \\
\hline Neuroticism & 3.250 & .042 \\
\hline Openness & 2.510 & .086 \\
\hline Consciousness & 2.310 & .104 \\
\hline
\end{tabular}

According the five factor model, neuroticism, and especially vulnerability and severity of anxiety is the most expressed personality dimension in young people with GAD, while the need order and dutifulness in the dimension consciousness is most apparent dimension of personality among youth with GAD and SP. Neuroticism is one of the best empirically validated dimensions and it is considered as the most important dimension associated with anxiety disorders (13). It means emotional instability, intolerance of stress and tends to destabilize the person under stressful circumstances. It represents a general tendency to experience negative emotions (sadness, anger, fear, anxiety, guilt, etc.) (14). This research shows that young people with anxiety disorders do not differ in terms of depression, aggression, and selfawareness and hostility but they show differences in vulnerability and the degree of anxiety. Young people with GAD constantly expressed restlessness, those with PD feel uncertainty about the occurrence of anxiety, while those with SP experience it only in certain social situations, and because of that they show differences in vulnerability, anxiety, achieving goals and order.

The results of numerous studies $(815,16,17,18,19)$ also show that youth people with different anxiety disorders appears to have high neuroticism, and the general conclusion is that neuroticism is one of the key factors of vulnerability, disposition to develop these disorders. During the development period occurrence of anxiety disorder leads to continuity in behavioral problems and cognitive distortions (4), leads to emphasizing certain traits and making those young people to become socially dysfunctional (20).

\section{REFERENCES}

1. Kassin, S. 2003. Psychology. USA: Prentice-Hall, Inc.

2. Eysenck, H. J., \& Eysenck, M. W. 1985. Personality and individual differences: A natural science approach. New York: Plenum.

3. Eysenck, H.J. 1967. The biological basis of personality. Springfield, IL: Thomas.

4. Matthews, G., Deary, I.J., \& Whiteman, M.C. 2003. Personality traits (2nd edition). Cambridge: Cambridge University Press.

5. Schacter, Gilbert, Wegner 2011. Psychology (2nd ed.). Worth. pp. 474-475.

6. McCrae, R. and Costa, P. 2003. Personality in Adulthood: A Five-Factor Theory Perspective. New York: The Guilford Press.

7. McCrae, R. and Costa, P. 2004. Cross-Cultural research Personality and Culture Revisited: Linking Traits and Dimensions of Culture, SAGE. 
8. McCrae, R. and Terracciano, A. 2005. Personality profiles of cultures: aggregate personality traits, Journal of personality and social psychology, Vol 89, No 3. 407-425.

9. McCrae, R. and John, P.O. 2006. An Introduction to the Five-Factor Model and Its Applications, Journal of personality, Vol 60 Iss 2.

10. Schwartz, C., Snidman, N., Kagan, J. 1999. "Adolescent social anxiety as an outcome of inhibited temperament in childhood". J Am Acad Child Adolesc Psychiatry 38 (8): 1008-1015. doi: $10.1097 / 00004583-199908000-00017$. PMID 10434493.

11. Heimberg, R.G., Stein, M.B., Hiripi, E., Kessler, R.C. February 2000. "Trends in the prevalence of social phobia in the United States: a synthetic cohort analysis of changes over four decades". Eur. Psychiatry 15 (1): $29-37$. doi: 10.1016/S0924-9338(00)00213-3. PMID 10713800.

12. Baumeister, R., Leary, M. 1995. "The need to belong: desire for interpersonal attachments as a fundamental human motivation". Psychol Bull 117 (3): 497-529. doi:10.1037/0033-2909.117.3.497. PMID 7777651.

13. Digman, J.M. 1990. Personality Structure: Emergence of the Five-Factor Model. Annual Review of Psychology; 41:417-440.

14. Knežević, G., Džamonja-Ignjatović, T., Đurić-Jočić, D. 2004. Petofaktorski model ličnosti. Beograd: Centar za primenjenu psihologiju.

15. Cuipers, P., Van Straten, A., Donker, M. 2005. Personality traits of patients with mood and anxiety disorders. Psychiatry Research: 133:229-237.

16. Bienvenu, O.J., Brown, C., Samuels, J.F., Liang, K.Y., Costa, P.T., Eaton, W.W. 2001. Normal personality traits and comorbidity among phobic, panic and major depressive disorders. Psychiatry Research: 102:73-85.

17. Bienvenu, O.J., Stein, M.B. 2003. Personality and anxiety disorders: A review. Journal of Personality Disorders: 17:139-151.

18. Bienvenu, O.J., Samuels, J.F., Costa, P.T., Reti, I.M., Eaton, W.W., Nestadt, G. 2004. Anxiety and depressive disorders and Five-factor model of personality: a higher and lower-order personality trait investigation in a community sample. Depress Anxiety: 20:92- 97.

19. Widiger, T.A., Trull, T.J. 1992. Personality and Psychopathology: An Application of the Five-Factor Model. Journal of Personality: 60:363-393.

20. Saucier, G., \& Goldberg, L. R. 1998. What is beyond the Big Five? Journal of Personality, 66, 495-524.

ul. Dobromir Hrs br.36b

1000 Skopje, Macedonia

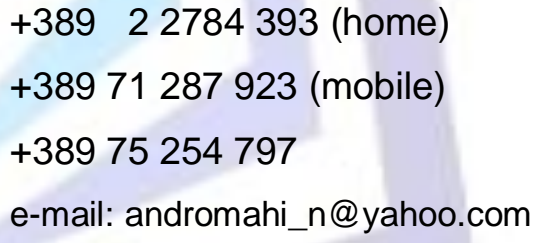

e-mail: andromahi_n@yahoo.com

\section{Author' biography with Photo}

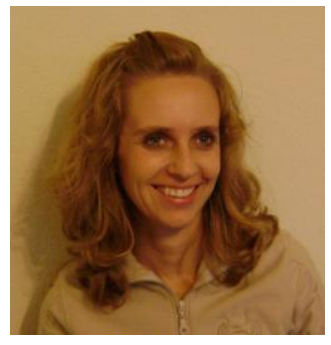

\section{NALMOVSKAANDROMAH}

Day of birth 29. 09. 77 Gevgelija

\section{Experience}

September 2009- present 
Gestalt institute "SHS”, Skopje, Gestalt therapist, trainer, supervisor

September 2002- present

Psychiatric hospital "Skopje”, Skopje, Spec. of Medical Psychology, Gestalt therapist January 2007- May 2009

Trust- association for improvement of prevention, treatment and social reintegration for persons on drugs, Counseling as Spec. of Medical Psychology, Gestalt therapist

September 2005- May 2007

HOPS, Skopje. Re-socialization and re-integration of drug abstinent

Coordinator, Psychologist, Gestalt therapist

January 2001 - September 2002

\section{CESVI World Aid from Italy, Skopje}

Social, Interactive and Non-formal Education Support for Refugees Children, Teenagers and Women in FYROM in relation with Ethnic Minorities and Host Communities

Psychologist

Field officer, supervision of the instructors, creating program, supervision of the implementation of the program, individual work with children or instructors, organizing seminars, making assessments, preparing new projects.

Distribution in conflict area in FYROM

Local project coordinator.

Sustain to activities in the rural conflict-affected areas in FYROM

Administrator.

September 2000- October 2001

PEKSNAS, (Rade Jovcevski Korcagin) Skopje, High school, Teacher of psychology March 2000 - July 2000

Institution of mental health for children and young, Skopje and UNICEF

Psychosocial Support and Training of School Age Children at Risk, Psychologist, Coordinator

September 1999 - May 2000

SOS Line for Children and Youth at the First Children's Embassy in the World "Medjasi"

Consulting work on the SOS line

May 1999 - December 2000

Center for Psychological Consultation, Institute of Psychology Philosophical Faculty -

Skopje and UNICEF

- Research work on several projects

Direct Psychosocial Support and Training of Refugees -

Support to Woman and Children at Risk in the Macedonian Collective Centers

- Researcher

- Psychologist- consultant

\section{Active Participation of Pupils in Crisis Situation}

- Facilitator in pupil workshops

\section{Education}

2012, M-r sc. of Developmental psychology 
St. Cyril \& Methodius University, Institute of Psychology

2009, Gestalt trainer, supervisor

Association of Gestalt therapy- Contact, Educator and supervisor, Koprova Biljana $2006-2008$

\section{Association of Cognitive-behavior therapy,}

270 hours Cognitive-behavior therapy, Educator and supervisor, Petar Vasilev

2007, Specialist of medical psychology

\section{St. Cyril \& Methodius University, Medical Faculty}

$2003-2004$

Course for Rorschach psycho diagnostic method, Mentor, Zdravkova Julka 2004, Gestalt therapist

Association of Gestalt therapy- Contact, Educator and supervisor, Koprova Biljana 1999, BA in Psychology

\section{St. Cyril \& Methodius University, Institute of Psychology}

\section{Publications}

- Naumovska A., Bonevski D.(2012). Self Image and Frequent Alcohol Use in Middle Adolescence. Journal of US-China Medical Science UCMS, 9(1): 38-45.

- Bonevski D., Novotni A., Raleva M., Naumovska A.(2012). Childhood Abuse and Level of Manifested Anxiety in Adult Patients with Anxiety Disorder. Macedonian Journal of Medical Science MJMS, 5(1): 94-98.

- Naumovska A., Bonevski D., Stoimenova V. (2012). Slikata za sebe i kreativnosta kaj adolescenti. Medikus, 14:12-13.

- Bonevski D., Naumovska A., Kiteva L., Novotni T. (2011). Kreativnost i psihodrama. Medikus, 13:12-13.

\section{Congress, conferences}

- 2013, Sofia, Bulgaria, International conference

- Bonevski D., Naumovska A., Lefkova K. Depression in Impulse control disorders

- Naumovska A., Bonevski D., Lefkova K. Attachment in Impulse control disorders

- 2013, Athens, Greece, International conference

- Bonevski D., Naumovska A., Jeremic M., Boskovska M. Resilience, anxiety and depression in internally displaced people

- Naumovska A.,Bonevski D., Jeremic M., Boskovska M. Self image and depression in adolescents internally displaced during their childhood

- Boskovska M., Bonevski D., Naumovska A., Jeremic M. Psychiatric Treatment in PTSD patients

- Jeremic M., Bonevski D., Naumovska A., Boskovska M. Postoperative anxiety and depression in women with Caesarea

- 2012, Ohrid, International conference

- Bonevski D., Naumovska A., Jeremic M., Boskovska M. Alcoholism and family violence

- Naumovska A., Bonevski D., Jeremic M., Boskovska M. Self image and parents with alcoholism

- 2012, Becici, Monte Negro, International conference

- Bonevski D., Naumovska A., Jeremic M., Boskovska M. Parental problem drinking and 


\section{ISSN 2278-7690}

panic disorder in adult offspring

- 2012, Belgrade, International conference

- Bonevski D., Naumovska A., Jeremic M., Boskovska M. Dysfunctional family and panic disorder in adult offspring

- Jeremic M., Bonevski D., Boskovska M., Naumovska A. Use of the selective serotonin reuptake inhibitor Escitalopram in the treatment of the depressive disorder

- Boskovska M., Naumovska A., Jeremic M., Bonevski D., Boskovska F., Blazevska E., Boskovska E. Case study

- 2012, Stettin, 21-ta International conference- Community development- reality, transition, future

- 2011, Belgrade, First international congress- Hospital psychiatry

- Jeremic M., Naumovska A., Bonevski D., Boskovska M. Psychosocial treatment in daily centre for mental health and patients anxiety

- Boskovska M., Jeremic M., Naumovska A., Bonevski D. Preventing relapse in patients with psychosis in daily centre for mental health

- 2011, Sofia, International conference- Sofia, Nis, Skopje

- Naumovska A., Jeremic M., Bonevski D., Boskovska M. Depressive symptoms among schizophrenic outpatients and patients in daily hospital

- Bonevski D., Jeremic M., Boskovska M., Naumovska A. Severity of negative symptoms among schizophrenic outpatients and schizophrenic patients in daily hospital

- Boskovska M., Jeremic M., Naumovska A., Bonevski D., Boskovska E. Case study: brain tumour in temporal region with depressive -paranoid syndrome

- Jeremic M., Bonevski D., Boskovska M., Naumovska A. Differences in manifest anxiety in patients with schizophrenia and bipolar affective disorder

- 2011, Brno, 20-th International conference - Dealing with the differences

- 2010, Skopje, International Psychiatric conference- Skopje, Nis Sofia

- Naumovska A., Boskovska M., Jeremic M., Bonevski D., Dukovska S. Cognitive functions in schizophrenic patients in remission

- Naumovska A., Boskovska M., Jeremic M., Bonevski D., Dukovska S. Schizophrenic patients and depression

- Jeremic M., Boskovska M., Naumovska A. Most common drugs in daily centre for mental health - Centre

- Jeremic M., Naumovska A. Case study- psychogenic deaf

- Boskovska M., Naumovska A., Boskovska F., Blazevska E., Jeremic M., Dukovska S., Bonevski D., Boskovska E. EEG and neurosis

- Boskovska M., Naumovska A., Boskovska F., Blazevska E., Jeremic M., Bonevski D. Olanzepine in treatment of psychosis

- 2010, Lviv, 19-th International conference, Social courage

- 2009, Mikulov, 18-th International conference, Young people and violence

- 2009, Ohrid, IV Macedonian and international psychiatric congress

- Boskovska M., Jeremic M., Naumovska A. Epilepsy and co-morbidity. 28-29

- Boskovska M., Jeremic M., Naumovska A. Schizophrenic patient and long lasting injections. 92-93

- Aleksovska N., Ignjatova L., Kostovski D., Kirkova N., Naumovska A. Diazepam in patients in methadone maintenance treatment. 104

- 2009, Skopje, International virtual e-hospital, Third Balkan seminar for telemedicine and ehealth

- 2007, Tirana, International virtual e-hospital, Second Balkan seminar for telemedicine and ehealth

Seminars -As educator: 
February 2009, Skopje Psychiatric hospital "Skopje" New medical programs for persons on drugs

October 2007, Popova Sapka Psychiatric hospital "Skopje". Team work in a treatment of persons on drugs

September 2007, Mavrovo Psychiatric hospital "Skopje”. Experience and achievement in the treatment of persons on drugs II

September 2007,Mavrovo Psychiatric hospital "Skopje". Experience and achievement in the treatment of persons on drugs I

May 2007, Pelister Psychiatric hospital "Skopje". Multi discipline approach in the treatment of persons on drugs as a improving factor

Seminars, conferences- As student:

May 2011, Skopje Centar za humani relacii, Gestalt therapy workshop, Dzani Franceseti, Italy

March 2011, Skopje Institute for Family therapy, Relationships, Nevena Caloska-Hercog, Serbia

January 2010, Skopje Centar za humani relacii, Gestalt therapy workshop, Dzani Franceseti, Italy

December 2009, Skopje Alchjamer desease

May 2009, Skopje Consultations for human collaboration, Workshop- gestalt therapy, Richard Lompa, Holand March 2009, Skopje Psychiatric hospital "Skopje", First national conference for treatment with substitution for persons on drugs

November 2008, Veles Association of psychiatrist RM, Sleeping disorder, Treatment of depression

November 2008, Veles Trust- association for improvement of prevention, treatment and social reintegration for persons on drugs, Working principals for psychosocial support for persons on drugs

October 2006, Mavrovo H.O.P.S., Preventive services for Most-at-risk populations II

September 2006, Mavrovo H.O.P.S., Preventive services for Most-at-risk populations I

December 2003, Skopje Macedonian consortium for international collaboration, Monitoring projects

May 2003, Skopje Consultations for human collaboration, Workshop- gestalt therapy, Harm Siemens

June 2002, Skopje Consultations for human collaboration, Workshop- gestalt therapy, Harm Siemens

June 2001, Skopje Center for human relations, Workshop- gestalt therapy, Harm Siemens

June 2001, Skopje Macedonian consortium for international collaboration, Creating and running projects

May 2001, Skopje Center for Psychological and crisis action, Institute of Psychology Philosophical Faculty - Skopje Helping to the helpers

December 2000, Skopje Center for Psychological Consultation, Institute of Psychology Philosophical Faculty - Skopje and UNICEF, The Pupils - Active Participants in the School May 2000, Struga Center for Psychological Consultation, Institute of Psychology Philosophical Faculty - Skopje and UNICEF, Psychosocial Help in Population at Risk: Working with Groups, Gay Grew of Southampton University, UK

April 2000, Ohrid Center for human relations, Workshop- gestalt therapy, Harm Siemens

March 2000, Skopje Center for Psychological Consultation, Institute of Psychology Philosophical Faculty - Skopje and UNICEF, Practical Training: Participation and conducting of 5 workshops with 4-th grade pupils

February 2000, Skopje Center for Psychological Consultation, Institute of Psychology Philosophical Faculty - Skopje and UNICEF, Provision of the pupils active participation in the IVAC Approach Stages

January 2000, Skopje Center for Psychological Consultation, Institute of Psychology Philosophical Faculty - Skopje and UNICEF, Provision of the Pupils Active Participation in the 
IVAC Approach Stages

January 2000, Skopje Center for Psychological Consultation, Institute of Psychology

Philosophical Faculty - Skopje and UNICEF, Active Competence and IVAC Approach

December 1999, Skopje Center for Psychological Consultation, Institute of Psychology

Philosophical Faculty - Skopje and UNICEF, The Pupils - Active Participants in the School

September 1999, Skopje Center for Psychological Consultation, Institute of Psychology

Philosophical Faculty - Skopje and UNICEF, Search for Common Ground

July 1999, Mavrovo Society for Psychological Assistance-Zagreb, Psychosocial First Aid June 1999, Skopje St. Cyril \& Methodius University Skopje, Balkan Peace Center, Alternatives to Violence Project

\section{Membership}

Macedonian Chamber of Psychology

Macedonian Association of Gestalt Therapy- MAGT

European Association of Gestalt Therapy- EAGT

Macedonian Association of Psychotherapy- MPA

European Association of Psychotherapy- EAP

\section{Language}

English

\section{Computer skills}

MS Word, MS Excel, Power point, Internet, SPSS 